Giménez Folqués, D. (2020): Evolución de los italianismos en los últimos diccionarios académicos del español. Cultura, Lenguaje y Representación, Vol. XXIII, 97-108

ISSN $1697-7750 \cdot$ e-ISSN $2340-4981$

DOI: http://dx.doi.org/10.6035/clr.2020.23.6

\title{
Evolución de los italianismos en los últimos diccionarios académicos del español
}

The evolution of italianisms in the last Spanish academic dictionaries

RESUMEN: En las últimas décadas, las voces de origen foráneo han aumentado su presencia en los diccionarios académicos del español debido, entre otros factores, a la mayor difusión de los medios de comunicación y a la evolución de la tecnología. Ante este caudal léxico, organismos oficiales como la Real Academia Española han intentado recoger y clasificar estas voces siguiendo, como punto de partida, su frecuencia de aparición en corpus académicos como el CORPES XXI. La influencia de idiomas como el inglés en el español ha sido ampliamente estudiada, sin embargo, la proyección de otros idiomas como el italiano, que también han aumentado su notoriedad, todavía necesitan aumentar su análisis para conocer su situación actual. Por lo tanto, en el presente trabajo trataremos de investigar la evolución de los italianismos en obras académicas vigentes como el Diccionario de la lengua española de la RAE, para observar qué voces se han modificado y cuáles se han incorporado a esta última obra. Otro punto de interés en esta investigación será comprobar los criterios que han seguido los organismos oficiales mediante el CORPES XXI para llevar a cabo estas modificaciones.

Palabras clave: CORPES XXI, italianismos, lexicografía española, lexicología española, RAE.

ABSTRACT: In recent years, foreign words have increased their presence in Spanish academic dictionaries. Given this situation, official organizations such as the Royal Spanish Academy have tried to collect and classify these voices following their frequency in academic corpus such as CORPES XXI. The influence of languages such as English in Spanish has been widely studied, however, the projection of other languages such as Italian still need to increase their study and analysis to know their current situation. Therefore, in the present work we will try to investigate the evolution of the Italianisms in current academic works such as the Diccionario de la lengua española of the RAE, to observe which voices have been modified and which have been incorporated into this last work. Another point of interest in this investigation will be to analyse the criteria that have been followed by CORPES XXI to carry out these modifications. 
Key words: CORPES XXI, Italianisms, Spanish lexicography, Spanish lexicology, RAE.

\section{ITALIANISMOS EN LOS DICCIONARIOS ACADÉMICOS ${ }^{1}$}

Como es sabido, la lengua española ha ido evolucionando a lo largo de la historia mediante el contacto lingüístico. Muchas han sido las lenguas con las que ha entrado en contacto como, por ejemplo, con el árabe, en la época de la conquista, o las lenguas amerindias, en la llegada a América. En cuanto a las lenguas europeas, tienen un papel destacable en nuestro idioma lenguas de cultura como el francés, el italiano y el inglés, que han aumentado su proyección en los últimos tiempos con la apertura de los medios de comunicación y los avances tecnológicos.

La lengua italiana tiene un papel destacado principalmente en el Renacimiento italiano, tal como señala Sánchez Mouriz (2015: 44):

Los italianismos alcanzaron su apogeo en los siglos XVI y XVII, debido al Renacimiento italiano y la participación de fuerzas armadas en la península italiana. La relación genética entre italiano y español y las similitudes entre sus estructuras fonológicas facilitaron la integración de las palabras italianas en la lengua española.

En este momento, el italiano es especialmente influyente en la temática de las artes como la pintura, la escultura, la arquitectura, la música, el teatro o la gastronomía en voces como «acuarela, adagio, arpegio, claroscuro, novela, ópera, pizza, soneto, soprano, violín».

En particular, entre las variedades del español, destaca la influencia italiana a finales del siglo XIX sobre la zona rioplatense americana. En ese momento, se produce un gran movimiento migratorio europeo debido a la apertura de puertas de Argentina hacia Europa. A esta llamada acuden principalmente italianos y españoles. Muchos de los migrantes italianos que desembarcan en territorio americano enraizaron en esta tierra dejando su cuño cultural y, por supuesto, lingüístico ${ }^{2}$. De esta manera, encontramos un notable número de voces que ingresaron, en un primer momento, en el español rioplatense y que, con el paso del tiempo, han acabado integrándose en el español general, como es el caso de «laburo, laburar, gambetear, morfar».

En cuanto a los organismos académicos como la Real Academia Española ${ }^{3}$ y la Asociación de Academias de la Lengua Española ${ }^{4}$ ha habido un intento por recoger, clasificar y adaptar todas las voces foráneas que han ido llegando al idioma. Por un lado, en su afán de reflejar el uso de la lengua no podían ser ajenos al empleo de voces de otros idiomas que se estaban dando con cierta frecuencia y temporalidad. Por el otro, ha existido siempre cierta cautela con este tipo de palabras, muchas veces ajenas a la ortografía y pronunciación españolas, y que en muchas ocasiones suplantaron voces patrimoniales. Es por ello por lo que se toma la determinación de adaptar los extranjerismos necesarios que no tienen un equivalente patrimonial y de aconsejar el uso

\footnotetext{
${ }^{1}$ Este trabajo se enmarca en el proyecto La atenuación pragmática en su variación genérica: géneros discursivos escritos y orales en el español de España y América (FFI2016-75249-P), financiado por el Ministerio de Economía y Competitividad.

2 Según Conde (2016: 85) «En 1887, el 52,8 \% de la población de Buenos Aires había nacido en el extranjero y la de nacionalidad italiana sobrepasaba en la ciudad el $32 \%$ del total de sus habitantes».

${ }^{3}$ A partir de ahora «RAE».

${ }^{4}$ A partir de ahora «ASALE».
} 
del equivalente español, cuando este existe, en el caso de los extranjerismos, denominados por la RAE, innecesarios 5 .

Como hemos comentado en el inicio, los italianismos ${ }^{6}$ participan en la apertura comunicativa que se produce en estas últimas décadas aportando nuevas voces a las ya establecidas en los diccionarios académicos como la 22. ${ }^{\mathrm{a}}$ edición del Diccionario de la lengua española, con fecha del 2001 o en el Diccionario panhispánico de dudas (2005). En este sentido, la 23. a edición del Diccionario de la lengua española, con fecha del 2014, contempla el trabajo realizado por sus obras predecesoras y actualiza su caudal léxico, también en cuanto a italianismos se refiere.

Para llevar a cabo estas actualizaciones estas obras se nutren de los corpus académicos con los que trabajan. De este modo, la última edición del diccionario se basa en el CORPES XXI (Corpus del Español del Siglo XXI), corpus que recoge textos del español, tanto orales como escritos, de todas las variedades del español. Con respecto a su última actualización, de diciembre de 2018, el CORPES XXI (versión 0.91) cuenta con más de 285000 documentos que suman alrededor de 286 millones de formas.

\section{ITALIANISMOS EN LA INVESTIGACIÓN FILOLÓGICA ACTUAL}

Pese a que resulta imprescindible un mayor estudio y análisis sobre los italianismos en las fuentes académicas actuales, sí encontramos investigaciones que han ayudado a contextualizar este fenómeno. En este sentido, encontramos trabajos como el de Ayala Simón (2002), que analiza la entrada de italianismos en el Diccionario de la Real Academia Española en su versión electrónica de 1992. Este acercamiento lo realiza desde la temática gastronómica debido a la importancia de la lengua italiana en este ámbito $\mathrm{y}$, también, a su enfoque dinámico y cambiante. El autor concluye señalando la falta de rigurosidad en las marcas etimológicas de la RAE para llevar a cabo la recogida de estos vocablos, rigurosidad que ha ido mejorando en las ediciones posteriores.

A continuación, Lliteras (2016) indica que las palabras de origen italorrománico registradas en la edición del Diccionario (DRAE 2003) ascienden a 660, donde 635 proceden del italiano estándar. Esta cifra es netamente inferior a la de otros idiomas en la misma edición del Diccionario, como, por ejemplo, las 2051 entradas de etimología galorrománica o los 1086 términos de procedencia germánica. La autora señala que esta desproporción se puede deber a los problemas etimológicos que ya señalaba Ayala Simón (2002). La misma autora añade que estos problemas tienen que ver con la falta de «claridad entre los italianismos directos y la mediación del italiano en la introducción sobre todo de cultismos y latinismos, pero también de germanismos y galicismos» (Lliteras, 2016: 113). De este modo, se vuelve a poner en evidencia la necesaria revisión etimológica en las siguientes ediciones del Diccionario.

Asimismo, en la siguiente y última edición del Diccionario (edición 23.a , año 2014), encontramos un aumento considerable de voces de origen italiano. El total de acepciones ${ }^{7}$ pertenecientes a voces italianas encontradas consta de 1522. Este aumento tiene que ver con el uso de nuevas voces del italiano, algunas ya sugeridas en el

\footnotetext{
${ }^{5}$ Gómez Capuz (2009) realiza una definición muy clarificadora de las palabras foráneas donde diferencia entre «préstamos», como préstamos adaptados a la lengua española, y «extranjerismos», como préstamos no adaptados.

${ }^{6}$ Definidos por la RAE (2014) como:

1. $\mathrm{m}$. Giro o modo de hablar propio y privativo de la lengua italiana.

2. $\mathrm{m}$. Vocablo o giro de la lengua italiana empleado en otra.

3. $\mathrm{m}$. Empleo de vocablos o giros italianos en distinto idioma.

${ }^{7}$ En este caso hablamos de acepciones, ya que había voces que existían en la anterior edición pero que adquieren ahora una nueva acepción.
} 
Diccionario panhispánico de dudas, como «osobuco, brócoli, carpacho», pero también con una revisión más rigurosa de aquellas voces que realmente tenían esta marca lingüística. En los próximos capítulos incluiremos de manera más detallada aquellas voces que se han añadido al DLE.

Por otro lado, desde un punto de vista transatlántico, Conde (2016) incide en la importancia del italiano en la evolución de la variedad rioplatense, principalmente a partir de finales del siglo XIX con la masiva migración italiana, que ya habíamos mencionado anteriormente. Destaca que es en ámbitos como el del tango donde más se deja notar esta presencia de préstamos italianos y acaban conformando el denominado «lunfardo», jerga que nace en los bajos fondos bonaerenses a finales del siglo XIX donde los italianismos, junto con otros procedimientos neolíticos, tienen una gran incidencia. Esta influencia va más allá del léxico, ya que también alcanza al ámbito semántico y al entonativo, principalmente en el español bonaerense.

Finalmente, otros autores que trabajaron la influencia del italiano en la lengua española fueron Terlingen (1943) y (1960), que realiza un minucioso análisis etimológico de estos préstamos, principalmente en su primera obra; Lapesa 1981, que enfoca esta influencia desde un punto de vista histórico y Penny (2006), autor que se centra principalmente en la adquisición de los denominados «italianismos léxicos».

\section{NUEVAS VOCES DEL ITALIANO EN EL DICCIONARIO DE LA LENUA ESPAÑOLA Y METODOLOGÍAS DE ANÁLISIS}

En el desarrollo de este trabajo utilizaremos como fuente principal de extracción de italianismos el $D L E$. Concretamente, analizaremos aquellas nuevas voces que el Diccionario ha incorporado con respecto a su anterior edición del 2001.

Seguidamente, utilizaremos el filtro de CORPES XXI para determinar si el factor de frecuencia de uso ha sido tenido en cuenta a la hora de incorporar estas nuevas voces. Hay que contemplar que este corpus recoge textos desde principios del siglo XXI, con lo cual, los resultados serán significativos con respecto a la anterior edición del Diccionario. Por lo tanto, para llevar a cabo este cometido vamos a incorporar fichas lexicográficas con la información que acabamos de detallar. Los apartados que completarán estas fichas serán voz, definición en DLE y frecuencia de aparición en el CORPES XXI (en las diferentes variedades del español):

Por otro lado, si el italianismo cuenta con variaciones de género o número, se incluirán todas las variantes en los resultados de frecuencia de uso, ya que se consideran parte del mismo fenómeno de adaptación. Por lo tanto, activaremos la casilla lema, además de la casilla forma, para permitir esta posibilidad ${ }^{8}$.

\footnotetext{
${ }^{8}$ Únicamente incluimos los resultados que tengan que ver con el significado señalado en la ficha, por lo que se desecha el resto.
} 
edición) $)^{9}$.

Tabla 1. Nuevas voces del italiano en el Diccionario de la lengua española (23. ${ }^{\mathrm{a}}$

\begin{tabular}{|c|c|c|}
\hline Lema $^{10}$ & Definición en DLE & $\begin{array}{l}\text { Frecuencia de uso en } \\
\text { CORPES XXI }\end{array}$ \\
\hline A capela & $\begin{array}{l}\text { 1. loc. adj. Dicho de una composición musical: } \\
\text { Cantada sin acompañamiento de instrumentos. } \\
\text { U. t. c. loc. adv. Cantaron a capela. }\end{array}$ & 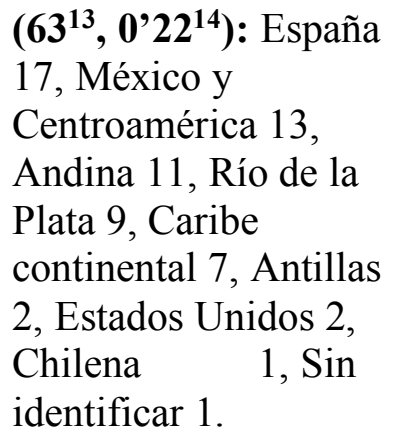 \\
\hline allegretto & $\begin{array}{l}\text { 1. m. Mús. Movimiento menos vivo que el } \\
\text { allegro. } \\
\text { 2. m. Mús. Composición o parte de ella que se } \\
\text { ha de ejecutar como allegretto. }\end{array}$ & 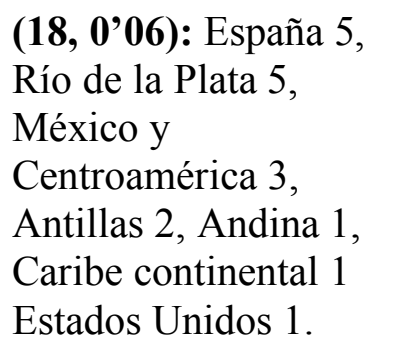 \\
\hline allegro & $\begin{array}{l}\text { 1. m. Mús. Movimiento moderadamente vivo. } \\
\text { 2. m. Mús. Composición o parte de ella que se } \\
\text { ha de ejecutar como allegro. Tocar o cantar un } \\
\text { allegro. }\end{array}$ & $\begin{array}{l}\mathbf{( 8 7 , 0 ’ 3 0 ) : ~ R i ́ o ~ d e ~ l a ~} \\
\text { Plata 23, España 22, } \\
\text { Caribe continental 15, } \\
\text { Antillas 10, México y } \\
\text { Centroamérica 9, } \\
\text { Andina 4, Chilena 3, } \\
\text { Estados Unidos } 1 .\end{array}$ \\
\hline altoparlante & 1. m. Am. altavoz. & $\begin{array}{l}\text { (291, 1’03): Río de la } \\
\text { Plata 66, Caribe } \\
\text { continental 49, Antillas } \\
\text { 48, Chilena 45, México } \\
\text { y Centroamérica 44, } \\
\text { Andina 27, Estados } \\
\text { Unidos 9, España 3. }\end{array}$ \\
\hline birra & 1. f. coloq. cerveza. & $\begin{array}{l}(\mathbf{1 4 1}, \mathbf{0} \mathbf{5 0}) \text { : España 61, } \\
\text { Río de la Plata 53, } \\
\text { México y }\end{array}$ \\
\hline
\end{tabular}

\footnotetext{
${ }^{9}$ Consulta realizada entre el 14/10/2019 y el 31/10/2019.

${ }^{10} \mathrm{Se}$ ordenan las voces alfabéticamente.

${ }^{11}$ Se mantiene la ortotipografía del DLE, cursiva o letra redonda.

${ }^{12}$ Los textos se recuperan desde el año 2001 hasta los más actuales.

${ }^{13}$ Número de apariciones en el corpus.

${ }^{14}$ Frecuencia normalizada. Casos por millón.
} 


\begin{tabular}{|c|c|c|}
\hline & & $\begin{array}{l}\text { Centroamérica 17, } \\
\text { Caribe continental 5, } \\
\text { Andina 2, Antillas 2, } \\
\text { Chilena 1. }\end{array}$ \\
\hline brócoli & $\begin{array}{l}\text { 1. m. Variedad de la col común, cuyas hojas, de } \\
\text { color verde oscuro, son más recortadas que las } \\
\text { de esta y no se apiñan. }\end{array}$ & $\begin{array}{l}\mathbf{( 5 3 8 , 1 9 9 1 ) : ~ E s p a n ̃ a ~} \\
\text { 126, Río de la Plata } \\
\text { 108, México y } \\
\text { Centroamérica 96, } \\
\text { Caribe continental 54, } \\
\text { Chilena 54, Andina 48, } \\
\text { Antillas 39, Estados } \\
\text { Unidos 12, Guinea } \\
\text { Ecuatorial 1. }\end{array}$ \\
\hline camerístico/a & $\begin{array}{l}\text { 1. adj. Perteneciente o relativo a la música de } \\
\text { cámara. }\end{array}$ & $\begin{array}{l}(\mathbf{3 3}, \mathbf{0} \mathbf{1 1}) \text { : España 21, } \\
\text { Río de la Plata } 4, \\
\text { Chilena 3, México y } \\
\text { Centroamérica 3, } \\
\text { Antillas 1, Caribe } \\
\text { continental } 1 .\end{array}$ \\
\hline cantabile & $\begin{array}{l}\text { 1. adj. Mús. cantable (\| que se debe interpretar } \\
\text { despacio). } \\
\text { 2. m. Mús. cantable (\| trozo de música). }\end{array}$ & $\begin{array}{l}(\mathbf{3 2}, \mathbf{0} \text { '11): España 14, } \\
\text { Río de la Plata 8, } \\
\text { Caribe continental 3, } \\
\text { Antillas 2, Chilena 2, } \\
\text { México y } \\
\text { Centroamérica 2, } \\
\text { Andina 1. }\end{array}$ \\
\hline capeleti & $\begin{array}{l}\text { 1. m. Arg., Par. y Ur. Pasta alimenticia rellena } \\
\text { de carne u otros ingredientes, doblada y unida } \\
\text { por sus bordes en forma de sombrero. U. m. en } \\
\text { pl. }\end{array}$ & $(\mathbf{0}, \mathbf{0})$ \\
\hline $\begin{array}{l}\text { carbonara / a la } \\
\text { carbonara }\end{array}$ & 1. adj. a la carbonara. Tallarines carbonara. & $\begin{array}{l}\text { (64, 0’22): España 31, } \\
\text { Caribe continental 15, } \\
\text { Andina 4, Chilena 4, } \\
\text { México y } \\
\text { Centroamérica 6, Río } \\
\text { de la Plata 3, Antillas } 1 .\end{array}$ \\
\hline carpacho & $\begin{array}{l}\text { 1. m. Plato compuesto de lonchas de carne o } \\
\text { pescado, cortadas muy finas y condimentadas } \\
\text { con diversas especias, que se come crudo. }\end{array}$ & $\begin{array}{l}(\mathbf{1 0}, \mathbf{0} \mathbf{0 3}) \text { : Río de la } \\
\text { Plata 3, Andina 2, } \\
\text { Caribe continental 2, } \\
\text { México y } \\
\text { Centroamérica 2, } \\
\text { España } 1 .\end{array}$ \\
\hline
\end{tabular}




\begin{tabular}{|c|c|c|}
\hline crocanti & $\begin{array}{l}\text { 1. m. Helado cubierto de una capa de chocolate } \\
\text { y trozos pequeños de almendra. }\end{array}$ & $\left(\mathbf{8}, \mathbf{0}^{\prime} \mathbf{0 2}\right)$ : España 8. \\
\hline cuartirolo & $\begin{array}{l}\text { 1. m. Arg., Par. y Ur. Variedad de queso blando } \\
\text { y cremoso, de origen italiano. U. t. c. adj. }\end{array}$ & $\begin{array}{l}\text { (9: 0’03): Río de la } \\
\text { Plata 9. }\end{array}$ \\
\hline decrescendo & $\begin{array}{l}\text { 1. adv. Mús. Disminuyendo gradualmente la } \\
\text { intensidad del sonido. } \\
\text { 2. m. Mús. Pasaje de una composición musical } \\
\text { que se ejecuta decrescendo. }\end{array}$ & $\begin{array}{l}(\mathbf{3}, \mathbf{0}, 01): \text { Andina } 1, \\
\text { Caribe continental } 1, \\
\text { España } 1 .\end{array}$ \\
\hline dismorfofobia & $\begin{array}{l}\text { 1. f. Psiquiatr. Fobia a padecer algún defecto, } \\
\text { anomalía o enfermedad que afecte } \\
\text { estéticamente a una parte del cuerpo, } \\
\text { especialmente al rostro. }\end{array}$ & $\begin{array}{l}\mathbf{( 7 , 0 ` 0 2 ) : ~ M e ́ x i c o ~ y ~} \\
\text { Centroamérica 3, Río } \\
\text { de la Plata 3, España } 1 \\
.\end{array}$ \\
\hline equilicuá & $\begin{array}{l}\text { 1. adv. coloq. U. para expresar asentimiento o } \\
\text { conformidad. ¡Equilicuá, tú lo has dicho! }\end{array}$ & $\left(\mathbf{8}, \mathbf{0}^{\prime} \mathbf{0 2}\right)$ : España 8. \\
\hline forte & $\begin{array}{l}\text { (aparece como 1. interj. U. para mandar hacer } \\
\text { alto en las faenas marineras.) } \\
\text { 2. m. Mús. En una interpretación, gradación } \\
\text { fuerte e intensa del sonido. } \\
\text { 3. adv. Mús. Con un sonido fuerte e intenso. } \\
\text { 1. adj. Mús. Dicho de un pasaje musical: } \\
\text { Ejecutado con un sonido fuerte e intenso. U. t. } \\
\text { c. s. m. }\end{array}$ & $\begin{array}{l}\text { (48, 0’17): España 31, } \\
\text { Caribe continental 4, } \\
\text { Chilena 4, México y } \\
\text { Centroamérica 3, } \\
\text { Andina 2, Antillas 2, } \\
\text { Río de la Plata 1, Sin } \\
\text { identificar 1. }\end{array}$ \\
\hline fortísimo/a & $\begin{array}{l}\text { 2. m. Mús. En una interpretación, gradación } \\
\text { muy fuerte e intensa del sonido. } \\
\text { 3. adv. Mús. Con un sonido muy fuerte e } \\
\text { intenso. } \\
\text { 1. adj. Mús. Dicho de un pasaje musical: } \\
\text { Ejecutado con un sonido muy fuerte e intenso. } \\
\text { U. t. c. s. m. }\end{array}$ & $\begin{array}{l}\mathbf{( 6 , 0 9 0 2 ) : ~ M e ́ x i c o ~ y ~} \\
\text { Centroamérica } 3, \\
\text { España } 2 \text {, Andina } 1 .\end{array}$ \\
\hline grafiti & $\begin{array}{l}\text { 1. m. Firma, texto o composición pictórica } \\
\text { realizados generalmente sin autorización en } \\
\text { lugares públicos, sobre una pared u otra } \\
\text { superficie resistente. }\end{array}$ & $\begin{array}{l}\text { (371, 1'31): México y } \\
\text { Centroamérica 95, } \\
\text { Caribe continental 67, } \\
\text { Río de la Plata 57, } \\
\text { España 56, Andina 34, } \\
\text { Antillas 31, Chilena 21, } \\
\text { Estados Unidos 5, } \\
\text { Guinea Ecuatorial 2, } \\
\text { Sin identificar 3. }\end{array}$ \\
\hline merdellón/a & $\begin{array}{l}\text { 1. adj. coloq. Dicho de una persona: Vulgar, } \\
\text { ordinaria. U. m. c. insulto. }\end{array}$ & (2, 0’00): España 2. \\
\hline
\end{tabular}




\begin{tabular}{|c|c|c|}
\hline minestrone & $\begin{array}{l}\text { 1. f. Sopa italiana de legumbres y de verduras } \\
\text { que a veces lleva pasta o arroz. U. t. c. m. }\end{array}$ & $\begin{array}{l}(\mathbf{2 5}, \mathbf{0} \mathbf{0 8}) \text { : España } 10, \\
\text { Andina } 7 \text {, México y } \\
\text { Centroamérica } 5, \\
\text { Caribe continental } 2 \text {, } \\
\text { Río de la Plata } 1 .\end{array}$ \\
\hline osobuco & $\begin{array}{l}\text { 2. m. Arg. y Chile. Corte del hueso del jarrete } \\
\text { vacuno, con su tuétano y la carne que lo rodea. }\end{array}$ & $\begin{array}{l}\mathbf{( 2 9 , 0 ’ 1 0 ) : ~ R i ́ o ~ d e ~ l a ~} \\
\text { Plata 11, Chilena 6, } \\
\text { España 6, Guinea } \\
\text { Ecuatorial 4, México y } \\
\text { Centroamérica } 2 .\end{array}$ \\
\hline pañolenci & $\begin{array}{l}\text { 1. m. Arg., Chile y Ur. Paño muy compacto que } \\
\text { se emplea especialmente en la confección de } \\
\text { gorros, muñecos y adornos. }\end{array}$ & $\begin{array}{l}\left(4,0^{\prime 01}\right): \text { Chilena } 2, \\
\text { Río de la Plata } 2 .\end{array}$ \\
\hline pascualina & $\begin{array}{l}\text { 1. f. Arg., Par. y Ur. Empanada rellena de } \\
\text { espinacas o acelgas y huevo duro. }\end{array}$ & $\begin{array}{l}\text { (67, 0’23): Río de la } \\
\text { Plata 46, México y } \\
\text { Centroamérica } 15, \\
\text { España 4, Chilena } 2 .\end{array}$ \\
\hline pesto & $\begin{array}{l}\text { 1. m. Salsa preparada con albahaca, piñones y } \\
\text { ajo machacados y aceite, con que se condimenta } \\
\text { especialmente la pasta italiana. }\end{array}$ & $\begin{array}{l}\text { (136, 0’48): España } 45, \\
\text { Chilena 34, Río de la } \\
\text { Plata 31, Caribe } \\
\text { continental 12, México } \\
\text { y Centroamérica } 7 \text {, } \\
\text { Andina 5, Antillas } 2 .\end{array}$ \\
\hline piccolo & 1. m. Mús. pícolo. U. t. c. adj. & $\begin{array}{l}(\mathbf{7 1}, \mathbf{0} \mathbf{2 5}) \text { : Río de la } \\
\text { Plata } 25, \text { España } 18, \\
\text { México y } \\
\text { Centroamérica } 10, \\
\text { Andina } 7, \text { Chilena } 6 \text {, } \\
\text { Caribe continental } 5 .\end{array}$ \\
\hline pichirilo & $\begin{array}{l}\text { 1. m. C. Rica, Ec. y Guat. Automóvil pequeño, } \\
\text { especialmente el viejo y destartalado. }\end{array}$ & $\begin{array}{l}\left(\mathbf{8}, \mathbf{0} \mathbf{0}^{\prime} \mathbf{2}\right) \text { : México y } \\
\text { Centroamérica } 7, \\
\text { Caribe continental } 1 .\end{array}$ \\
\hline pícolo & $\begin{array}{l}\text { 2. adj. Mús. Dicho de un instrumento: Que tiene } \\
\text { el tamaño más pequeño o la afinación más } \\
\text { aguda de los de su familia. Trompeta pícolo }\end{array}$ & $\begin{array}{l}(\mathbf{1 2}, \mathbf{0} \mathbf{0 4}) \text { : México y } \\
\text { Centroamérica } 6, \\
\text { España } 2, \text { Río de la } \\
\text { Plata 2, Andina 1, } \\
\text { Caribe continental } 1 .\end{array}$ \\
\hline pirotín & $\begin{array}{l}\text { 1. m. Arg., Ec. y Ur. Molde de repostería } \\
\text { pequeño para hacer dulces. }\end{array}$ & $\begin{array}{l}(3, \mathbf{0} \mathbf{0 1}) \text { : Río de la Plata } \\
\text { 2, Caribe continental } 1 .\end{array}$ \\
\hline putiferio & 1. m. coloq. puterío (\| prostitución). & $\begin{array}{l}(\mathbf{1 2}, \mathbf{0} 04): \text { España } 11, \\
\text { Río de la Plata } 1 .\end{array}$ \\
\hline
\end{tabular}




\begin{tabular}{|c|c|c|}
\hline & $\begin{array}{l}\text { 2. m. coloq. puterío (\| conjunto de personas que } \\
\text { ejercen la prostitución). } \\
\text { 3. m. coloq. puterío (\| situación de desmadre). }\end{array}$ & \\
\hline rúcula & $\begin{array}{l}\text { 1. f. Planta mediterránea cuyas hojas se utilizan } \\
\text { en ensalada o cocinadas. }\end{array}$ & $\begin{array}{l}(\mathbf{1 2 7}, \mathbf{0 , 4 5 )} \text { : Río de la } \\
\text { Plata 53, España } 32 \text {, } \\
\text { Chilena 26, Antillas 6, } \\
\text { Caribe continental 6, } \\
\text { México y } \\
\text { Centroamérica } 4 .\end{array}$ \\
\hline sottovoce & 1. adv. En voz baja, en secreto. & $\begin{array}{l}(\mathbf{1 3}, \mathbf{0} \mathbf{0 4}): \text { España } 6, \\
\text { Antillas 3, Chilena 2, } \\
\text { Río de la Plata } 2 .\end{array}$ \\
\hline tortellini & $\begin{array}{l}\text { 1. } \mathrm{m} \text {. Pasta alimenticia en forma de anillos, } \\
\text { rellena de carne, verdura o queso fresco. U. m. } \\
\text { en pl. }\end{array}$ & $\begin{array}{l}(\mathbf{2 3}, \mathbf{0} \mathbf{0 8}) \text { : España } \mathbf{1 5} \text {, } \\
\text { México y } \\
\text { Centroamérica } 4, \\
\text { Andina } 2 \text {, Caribe } \\
\text { continental } 1 \text {, Chilena } \\
1 .\end{array}$ \\
\hline
\end{tabular}

\section{RESULTADOS Y CONCLUSIONES}

Como podemos observar, en la última edición del Diccionario encontramos 34 nuevas voces con referencia a los italianismos. De entre estas voces, como podemos ver en la ilustración 1, predominan claramente las temáticas de la gastronomía (15 voces) y la música (10 voces), ámbitos que desde el Renacimiento italiano vienen aportando nuevas palabras a la lengua española.

\section{Ilustración 1. Temática de los italianismos}

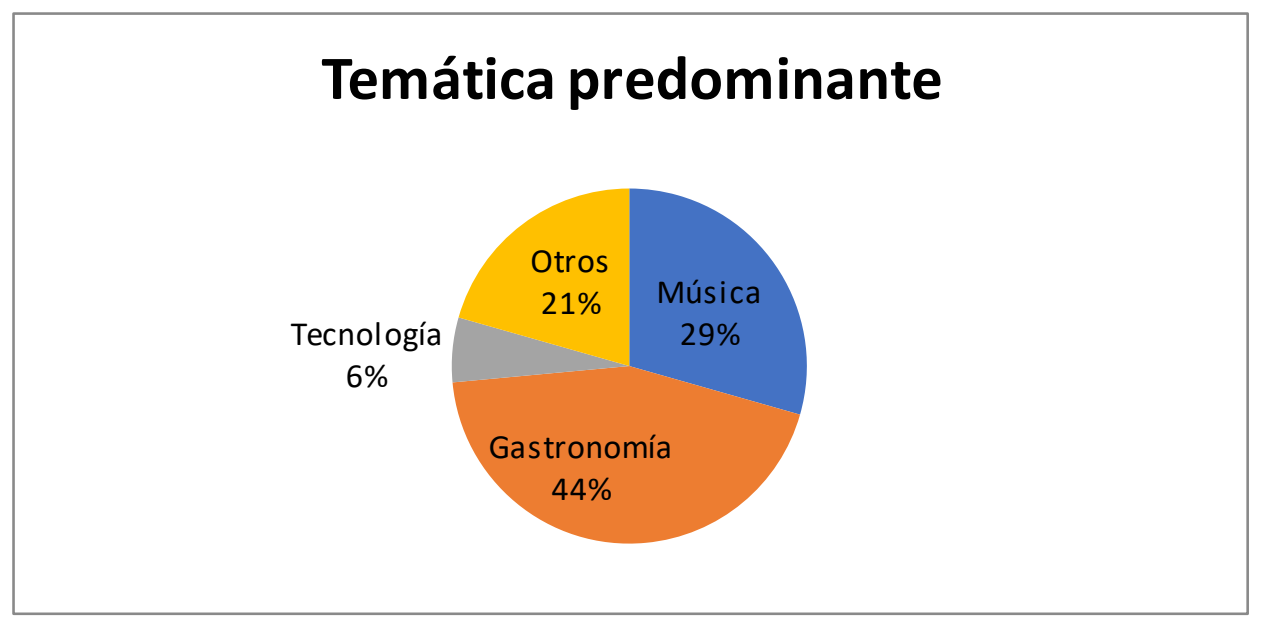

- Música: «a capela, allegretto, allegro, camerístico/a, cantabile, decrescendo, forte, fortísimo/a, piccolo, pícolo» 
- Gastronomía: «a la carbonara/carbonara, birra, brócoli, capeleti, carpacho, crocanti, cuartirolo, minestrone, osobuco, pascualina, pesto, pirotín, rúcula, tortellini»

- Tecnología: «altoparlante, pichirilo»

- Otros: «dismorfofobia, equilicuá, merdellón/a, pañolenci, putiferio, sottovoce, grafiti»

Asimismo, cabe destacar el alto grado de adaptación a la lengua española de este caudal léxico debido a que la mayoría de voces aparecen adaptadas a las características lingüísticas del español, 28 voces adaptadas frente a 7 italianismos escritos en su forma original.

De entre estos nuevos italianismos, ya aparecieron en el Diccionario panhispánico de dudas, en el año 2005, voces como «brócoli, carpacho, osobuco». Estas voces surgieron como propuesta de adaptaciones que se han mantenido en la última edición del Diccionario debido, entre otros factores, a su presencia en los corpus académicos: «brócoli (538)», «carpacho (10)», «osobuco (29)». El mismo DPD lanzó otras propuestas que, sin embargo, no han sido incluidas en esta última edición. Es el caso de «mozarela (0)», «mesosoprano (2)» y «paparazi (0)», con escasa presencia en el CORPES XXI, no como sucede con las voces originales de las que proceden: «mozzarella (167)», «mezzosoprano (180)» y «paparazzi (350)», que sí han sido incluidas en el Diccionario.

En cuanto a las zonas geográficas que más italianismos aportan encontramos España (frecuencia de 559) y el Río de la Plata (frecuencia de 528). En España, desde el Renacimiento italiano, la aportación de italianismos ha sido notable, como hemos explicado en un principio. También influye la gran presencia de textos peninsulares en el CORPES XXI con respecto al resto de zonas ${ }^{15}$. Por otro lado, la influencia italiana en contextos como el de Argentina es notoria desde finales del siglo XIX. Como podemos observar en la ilustración 2, este caudal léxico ha conseguido establecerse en el vocabulario del español general mediante sus diccionarios. Asimismo, llama la atención la aparición de variedades como Estados Unidos (30), donde el español toma cada vez más importancia, pero no es lengua oficial, o Guinea Ecuatorial (17), antigua colonia española donde el español aparece cada vez más fragmentado.

\footnotetext{
${ }^{15}$ El porcentaje de textos peninsulares sigue siendo superior al resto de variedades del español, aunque el número de textos en las variedades americanas ha aumentado en CORPES XXI con respecto al CREA (edición anterior del corpus).
} 


\section{Ilustración 2. Frecuencia de uso por zona}

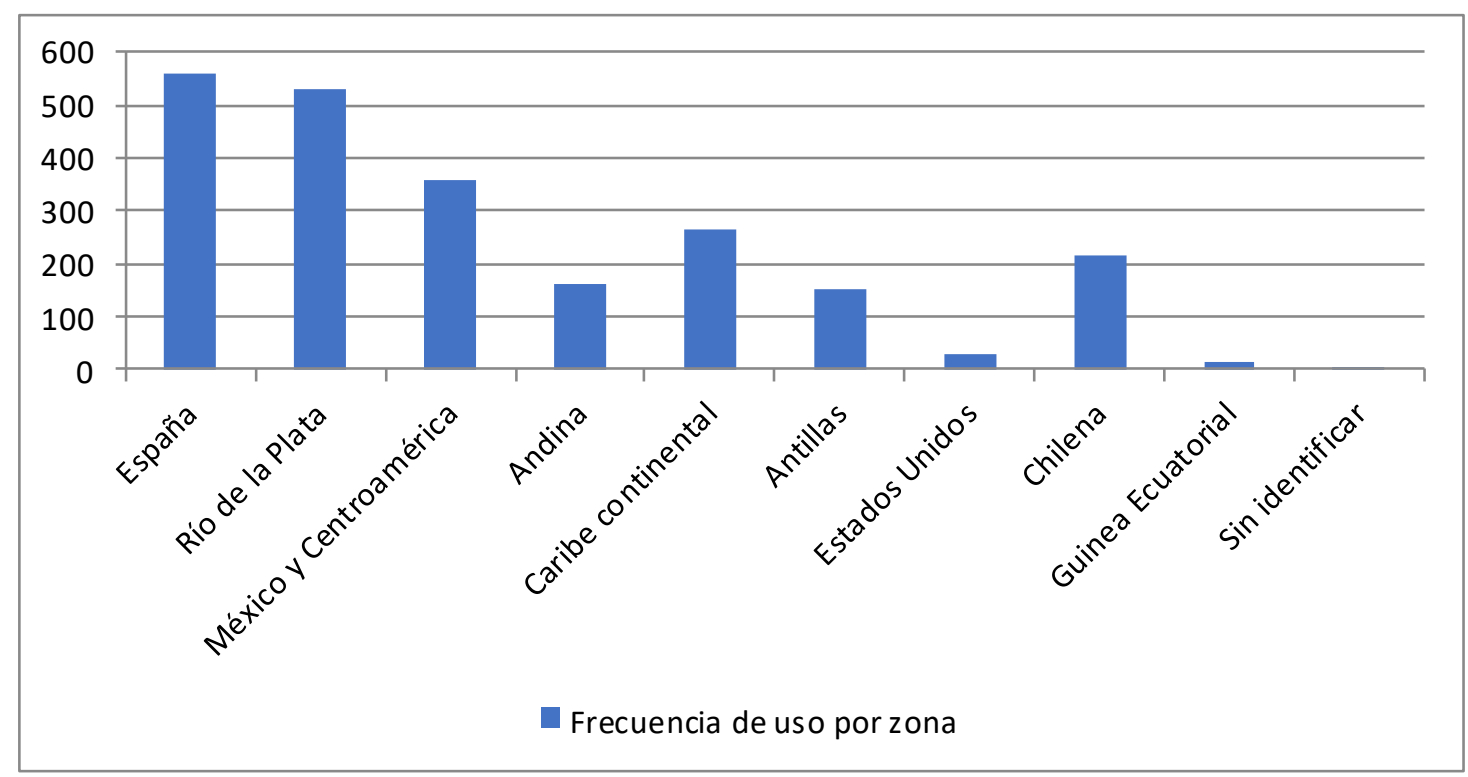

Por otro lado, es destacable la presencia de variantes entre los italianismos que hemos encontrado, ya que, por ejemplo, en la 22. ${ }^{a}$ edición del Diccionario sí aparecía «bróculi» y «brécol», que se mantienen en la última edición. Sin embargo, se ha incorporado la voz «brócoli (538)» a las dos primeras variantes debido a su alto rango de frecuencia de uso, factor, de nuevo, determinante para tomar una decisión de inclusión léxica.

En cuanto a las voces originales y sus adaptaciones también encontramos diferentes variantes. Por ejemplo, en la 22. ${ }^{a}$ edición del Diccionario aparecía la adaptación «alegreto», sin embargo, en la última edición se elimina a favor de «allegretto». Si acudimos al factor de frecuencia de uso en el CORPES XXI, observamos cómo «allegretto (18)» tiene mayor frecuencia que «alegreto (0)», que no aparece en el corpus. También encontramos el fenómeno contrario en «osobuco (29)», forma adaptada que se añade en detrimento de «ossobuco (5)», voz original de esta adaptación con menor frecuencia que la forma adaptada. En cambio, en el caso de «carpaccio (215)», «piccolo (71)» y sus adaptaciones «carpacho (10)», «pícolo (12)» el Diccionario decide mantener ambas formas, ya que tienen presencia en los corpus académicos.

Según los fenómenos que acabamos de analizar y retomando, de este modo, el principal objetivo de este trabajo, podemos afirmar que los organismos académicos como la RAE sí tienen en cuenta la frecuencia de uso en los corpus académicos de los que se sirven para realizar modificaciones en la incorporación de extranjerismos, en este caso, de italianismos. En la mayoría de nuevos italianismos que se han incorporado encontramos un ratio de frecuencia de uso en el CORPES XXI, corpus que conforma la base de la última edición del Diccionario. En este sentido destacan voces como «brócoli (538)», «grafiti (371)», «altoparlante (291)», «birra (141)», «pesto (136)» o «rúcula $(127) \gg$.

Por el contrario y como excepción, encontramos el caso de «capeleti (0)». Esta voz ha sido incorporada a la última edición del Diccionario, sin embargo, no aparece registrada en el corpus. La explicación que encontramos con respecto a que los usuarios no usen esta voz es la preferencia por el extranjerismo original que sí aparece registrado: «cappelletti (4)». Sin embargo, el extranjerismo crudo no aparece recogido por el 
Diccionario. Con lo cual, en las próximas ediciones, la RAE deberá estar atenta al desarrollo de esta voz y a la preferencia de los hablantes.

Otros casos con baja frecuencia son «decrescendo (3)», que aunque tiene cierta presencia los hablantes prefieren la voz «diminuendo (9)». En el caso de «pañolenci (4)», «pirotín (3)» y «merdellón (2)» la baja frecuencia de uso podría ser debida a que estamos hablando de formas muy específicas de una zona dialectal concreta, el Río de la Plata en el caso de «pañolenci» y «pirotín» y España en el caso de «merdellón». En definitiva, pese a estas excepciones, queda constatado el factor de frecuencia de uso como parámetro de inclusión léxica, por lo que estamos hablando de un fenómeno dinámico y cambiante que conlleva la continua revisión por parte de los organismos encargados de reflejar la actualidad del vocabulario español en sus obras lexicográficas.

\section{REFERENCIAS BIBLIOGRÁFICAS}

Ayala Simón, Eduardo. 2002. «Italianismos en DRAE 1992 (versión electrónica), heterogeneidad en las marcas del sector de las comidas». En Atti del XX Convegno [Associazione Ispanisti Italiani], coords. Domenico Antonio Cusato y Loretta Frattale. Firenze: Andrea Lippolis, 37-50.

Conde, Óscar. 2016. «La Pervivencia de los Italianismos en el Español Rioplatense». Gramma, XXVII, 57: 83-89.

Gómez Capuz, Juan. 2009. «El tratamiento del préstamo lingüístico y el calco en los libros de texto de bachillerato y en las obras divulgativas». Tonos, 17, 1-24.

Lapesa, Rafael. 1981. Historia De La Lengua Española. Madrid: Gredos.

Lliteras, Margarita. 2016. «Problemas lexicográficos de los préstamos italianos en español». En Actes du XXVIIe Congrès Internacional de Linguistique et de Philologie Romanes, Nancy, 15-20 de julio de 2013, section 11 Linguistique de contact, eds. Éva Buchi, Jean-Paul Chauveau y Jean Marie Pierrel. Strasbourg: Éditions de Linguistique et de Philologie, vol. 2, pp. 1245-1255.

Penny, Ralph J. 2006. Gramática Histórica del Español. 2. ${ }^{\mathrm{a}}$ ed. Barcelona: Ariel.

Real Academia Española. 1992. Diccionario de la Real Academia Española. Madrid: Espasa, ed. electróncia.

Real Academia Española. 2001 (22. ${ }^{\text {a }}$ ed.). Diccionario de la Real Academia Española. Madrid: Espasa.

Real Academia Española. 2003. Diccionario de la Real Academia Española, Madrid: Espasa, ed. electrónica.

Real Academia Española y Asociación de Academias de la Lengua Española. 2005. Diccionario panhispánico de dudas. Madrid: Espasa.

Real Academia Española: Banco de datos (CORPES XXI) [en línea]. Corpus del Español del Siglo XXI (CORPES). <http://www.rae.es> [Consulta: del 14-10-2019 al 3110-2019].

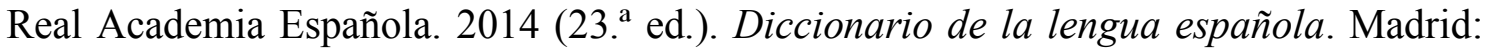
Espasa-Calpe.

Sánchez Mouriz, Héctor. 2015. «Préstamos Lingüísticos en la Lengua Española Actual: Italianismos, Latinismos, Arabismos, anglicismos y Galicismos». International Journal of Language and Linguistics, 2 ( 1): 41-53.

Terlingen, J. H. 1943. Los italianismos en español desde la formación del idioma hasta principios del siglo XVII. Amsterdam: Noord-Hollandsche Uitgeversmaatschappij.

Terlingen, J. H. 1960. «Italianismos». En Enciclopedia Lingüística Hispánica, ed. Manuel Álvar. Vol. 2. Madrid: CSIC, pp. 263-305. 